\title{
Challenges and lessons from conducting audit research using social media
}

\author{
Ahmed Saadeh* \\ Centre for Business and Enterprise, \\ Wintec, \\ Private Bag 3036, Waikato Mail Centre, \\ Hamilton 3240, New Zealand \\ Email: ahmed.saadeh@wintec.ac.nz \\ *Corresponding author
}

\section{Jackie Allen}

School of Accounting, Finance and Economics,

Faculty of Management,

University of Waikato,

Hamilton, New Zealand

Email: jnallen@waikato.ac.nz

\begin{abstract}
Social media play an increasingly important role as both a means of communication and a source of information. Furthermore, social media provide a variety of time and cost-efficient, as well as participant-friendly, communication and networking channels, which expand the research repertoire in terms of recruitment and conducting interviews. The purpose of this paper is to broaden researchers' understanding of the potential of using social media to facilitate qualitative research, and to guide them in the selection and use of social media channels considering the contextual differences. This paper adopts a qualitative methodology aimed at reflecting on the researcher's experience of recruiting participants and conducting interviews using social media. The paper is the first of its kind to explore the potential of incorporating social media as a tool in qualitative research while considering contextual and cultural factors.
\end{abstract}

Keywords: social media; qualitative research; accounting research; culture; context; reflexivity; recruitment; data collection.

Reference to this paper should be made as follows: Saadeh, A. and Allen, J. (2020) 'Challenges and lessons from conducting audit research using social media', Int. J. Economics and Accounting, Vol. 9, No. 4, pp.353-373.

Biographical notes: Ahmed Saadeh is a Principal Academic Staff Member in the Centre for Business and Enterprise at Waikato Institute of Technology (Wintec), New Zealand. He completed his $\mathrm{PhD}$ at the University of Waikato. His research interests include forensic accounting, accounting for the public good, accounting curricula reform, and qualitative accounting research.

Jackie Allen is a lecturer at the University of Waikato. She holds a Master's thesis in Accounting (AUT). She is a Chartered Accountant member of the Chartered Accountants Australia + New Zealand. Her research interests include sustainability and stakeholders, financial reporting issues, audit and accounting education. 


\section{Introduction}

In an August 2015 post on his personal page, Mark Zuckerberg, Facebook's co-founder and CEO, stated: "For the first time ever, one billion people used Facebook in a single day... and it's just the beginning of connecting the whole world."

Due to the exponential increase in internet use and advances in communication technology over the last decade, social media have become exceedingly popular (Acar, 2008; Kaplan and Haenlein, 2010). Social media play an increasingly important role as both a means of communication and a source of information. According to Digital Statshot Report (2015), the number of worldwide active social media users passed 2 billion in 2015, representing approximately third of the world's population. Furthermore, GlobalWebIndex (2014) found that the average social media user spends $2 \frac{1}{2}$ hours of his/her daily online time on social media websites.

Increased focus on social media stimulated a flow of studies that investigate the impact of social media on different aspects of individuals' lives in areas such as: health (Lee et al., 2014); behaviour (Mano, 2014); ethics (Ayres, 2013); relations (Williams and Merten, 2011); learning (Thomas and Thomas, 2012) and personal preferences (Bronner and de Hoog, 2014). While social media have drawn the attention of researchers in different fields, only a few of studies (e.g., Mangold and Faulds, 2009; Verkamp, 2013) explore the usage of social media in qualitative research. Research performed by Mangold and Faulds (2009) and Verkamp (2013) has shown that social media can foster participants' involvement in research. Valkenburg et al.'s (2006) study evidences the positive effect social media usage can have on the quality of collected data, while Gustafson and Woodworth (2014) and Lunnay et al. (2015) examine the methodological and ethical issues in research using social media.

According to Rosenbaum and Wong (2012), people are feeling increasingly more comfortable and familiar with communication technology, including social media. Lunnay et al. (2015) indicate that this level of confidence extends to research, which in order to accommodate modern day communication preferences requires recognising social media as a form of communication. Social media provide a variety of time and cost-efficient, as well as participant-friendly, communication and networking channels, such as instant messaging (IM) and digital media sharing, which expand the research repertoire in terms of recruitment and building rapport. Despite the potential advantages of social media, many researchers still focus primarily on traditional communication methods when engaging in qualitative research.

To the best of our knowledge to-date, no research in audit has been conducted using social media as a tool. The purpose of this paper is to broaden researchers' understanding of the potential of using social media to facilitate qualitative research, and to provide a guide in the selection and use of social media channels. Based on experiences in conducting 40 semi structured interviews as the primary data collection method for forensic audit research, this paper offers reflective insights into using social media in qualitative research. The challenges experienced while conducting in-depth interviews within a Jordanian context are explained and guidance is provided on how to address these challenges.

This paper contains five further sections. The next section provides a brief description of the research project. Thereafter, the features and characteristics of the key social media communication channels are reviewed. In Section 4, criticisms against the face-to-face interviews are reviewed. Some contextual dilemmas that emerged during the study are 
reflected on in Section 5, and some recommendations for using social media are presented. Section 6 provides a conclusion to the paper.

\section{Context of research}

In the aftermath of the recent global financial scandals, there has been a negative perception of auditors' independence, and of the effectiveness of traditional audit procedures to protect users from fraudulent financial reporting (Hao, 2010; Huber, 2012). Shanikat and Khan (2013) emphasise the growing need for professional accountants to understand the area of financial statement fraud, while Siegel and Shim (2010) identify the need for accountants who have deeper understanding of fraud as forensic accountants.

Despite the growing need for accountants with forensic accounting skills, limited background information exists with respect to forensic accounting education in the context of developing countries and in particular relating to Jordan (Elitas et al., 2011; Shanikat and Khan, 2013; Alabdullah et al., 2014). The way in which accounting practices are taught in developing countries, and the solutions to their unique problems, requires a different approach when compared to Western countries. Hence, business schools should consider cultural and contextual differences when developing and implementing a forensic accounting education programme.

The overall objective of the base research is to develop a framework for a forensic accounting programme compatible with Jordan's unique culture and business environment. This research provides a unique contribution by developing a forensic accounting education program, in an attempt to fill the gap between forensic accounting demand and supply in Jordan. Forty in-depth interviews were conducted, with accounting academics and practitioners, to capture experiences and viewpoints surrounding the development of a framework for teaching forensic accounting in Jordan.

\subsection{Constructing the interview questions}

In order to create effective research questions, the researchers, as suggested by Kvale and Brinkmann (2009) reviewed the literature and context theories relating to the topic. One of the researchers, a Jordanian Muslim, with bilateral experience first as an accounting student and then as an accountant and auditor in Jordan further enhanced familiarity with the topic.

Although intended for Arabic speaking participants, interview questions were developed in English as English is widely spoken in Jordanian education institutions and the business environment. Participants were provided with a choice of responding in either Arabic or English. A 'double back-translation process' developed by Brislin (1980) was used, whereby questions were translated into Arabic by a translator and then translated back into English by another translator. The translation was then compared with the original English text to see if the two versions matched. Any changes were applied to the original translation and the final draft checked by an Arabic literature professor.

The majority of the participants chose to conduct the interviews in Arabic, although switching between Arabic and English frequently happened in most of the interviews. Filep (2009) explains that the researcher and the participant may be more able to explain certain issues in one language rather than the other. Therefore, code-switching "should 
not be regarded as a problem, but rather as a method that supports the communicative process" [Filep, (2009), p.64].

\section{Literature review - social media}

There is no universally recognised definition of social media (Verkamp, 2013). Even the terminology remains unclear with some in the literature using the term 'social network' (e.g., Belew, 2014; Kent and Leaver, 2014) to refer to the same concept (Langmia et al., 2013). Google Trends (2015) for 'social media' versus 'social network' show that use of the former term has steadily increased since 2012. For the purpose of this paper, the term 'social media' is used and defined as "websites and applications that enable users to create and share content or to participate in social networking" (Oxford Dictionaries, 2015b). In turn, 'social networking' is defined as the use of social media "to communicate with other users, or to find people with similar interests to one's own" (Oxford Dictionaries, 2015c).

Among the key functions social media have in common are networking, communicating, and sharing content (Lunnay et al., 2015). However, social media websites and applications exhibit (or assign) varying degrees of focus to these key functions (Digital Statshot Report, 2015). In general, the so-called IM applications such as WhatsApp, Viber, and WeChat are focused on communicating via messaging and calling, as well as sharing photos and videos (Statista, 2015). However, IM applications are not ideal for networking, as users usually need the mobile number or usernames of other users in order to add them to their contacts list (Social Compare, 2015).

Conversely, social media websites such as Facebook, Twitter, and LinkedIn are centred on networking with family, friends, people with similar interests, and public figures, as well as the posting of comments, photos, and other media content (Mahan et al., 2015; Kaplan and Haenlein, 2010). Social media websites make it easy to find fellow users by providing several networking features, such as a search bar where the user can type in the name or e-mail address of the user he or she is looking for, and the ability to import contacts from e-mail accounts (Quan-Haase and Young, 2010).

Wright (2005) indicates that each communication channel has advantages and disadvantages, and that there is no one best communication channel for all situations. Consequently, the features and characteristics of each communication channel should be clearly understood by the researcher so that the best channel for each particular context can be selected, enabling more effective communication. In the following subsections, the features and characteristics of the key social media communication channels are reviewed in the light of the observations obtained through conducting research.

\subsection{IM applications}

The developers of IM applications work on creating all-in-one applications where users can stay connected through a user-friendly, cost-efficient, and high quality service (Parsons and Woolley, 2013). As the world becomes more digital, people are gravitating toward instant, interactive conversations that take place on keyboards rather than to voice and video calls (Kim et al., 2008; Suki et al., 2011). IM and free audio and video calling have become common forms of communication, replacing traditional communication 
channels such as e-mails, SMS, and phone calls as preferred forms of communication (Church and de Oliveira, 2013; Gungl et al., 2014).

\subsubsection{Instant messaging}

IM is a text-based communicating service that enables individuals to communicate in real-time over the Internet through a software application (Yoon et al., 2014). IM falls somewhere in the middle between e-mail or SMS, and voice conversation. IM combines the advantages of e-mail, in that it is non-intrusive, versatile, and cost-efficient, with those of SMS, which is time-efficient and accessible, and the interactive conversational nature of the voice conversation (Peslak et al., 2010).

IM allows the person talking to interact with the listener in an immediate back-andforth discussion. However, unlike in traditional conversation, partners in IM can disconnect and reconnect without a need to apologise or feel disconnected (Garrett and Danziger, 2007). IM also enables the user to conduct multiple, separate chats at the same time, as well as to create a group conversation between several people (Schwarz, 2011). Moreover, unlike e-mails and SMS, the users of IM will usually be able to get check marks that indicate that the message has been successfully sent, received, and read. These checks help to make IM more interactive. Users can also indicate whether they are 'available, 'busy', 'away', or ask that others 'do not disturb' via a status setting (Garrett and Danziger, 2007). The status setting functions as a kind of answering machine, which enables the user to respond when he/she feels it is convenient.

The 'typing' indicator is another feature that creates a high-involvement communication mode in IM (Buchenscheit et al., 2014). In oral communication, the listener senses whether others have finished making a point as their voices and intonation go down, and they usually leave a pause to let the other person talk. This information is missing in other text-based communication channels such as e-mails and SMS. However, an indicator in IM compensates for this missing feature (Lancaster et al., 2007), as a 'typing' indicator appears whenever the other party is typing an instant message, thus pacing the conversation.

One of the main criticisms levelled at qualitative data gathered via online ${ }^{1}$ and telephone research is the lack of visual cues (Shuy, 2003). This deficit also results in the loss of a number of other elements: non-verbal data such as facial expressions and body language (Groves, 1990; Novick, 2008); contextual data such as the physical features of the respondent and the environment (Patton, 1990); and, verbal data and spoken words (Herzog and Rodgers, 1988). These types of data loss or distortion create challenges in the communication process which in turn may harm data quality (Carr and Worth, 2001). However, proponents of qualitative telephone and online research argue that many ways of compensating for the absence of non-verbal responses are available, such as intonation (Opdenakker, 2006); hesitations and sighs (Sturges and Hanrahan, 2004); and, emoticons (Elsbach and Bechky, 2009).

The ability to share emoticons is another unique feature of IM. Emoticons (see Figure 1), also known as smileys and emoji, have attracted considerable attention as a visual digital language to express emotion and intentions (Jibril and Abdullah, 2013). Users believe that emoticons can be richly expressive and compensate for the missing visual cues in online communication (Hsieh and Tseng, 2015; Skovholt et al., 2014). 
Figure 1 A sample of commonly used emoticons on social platforms (see online version for colours)

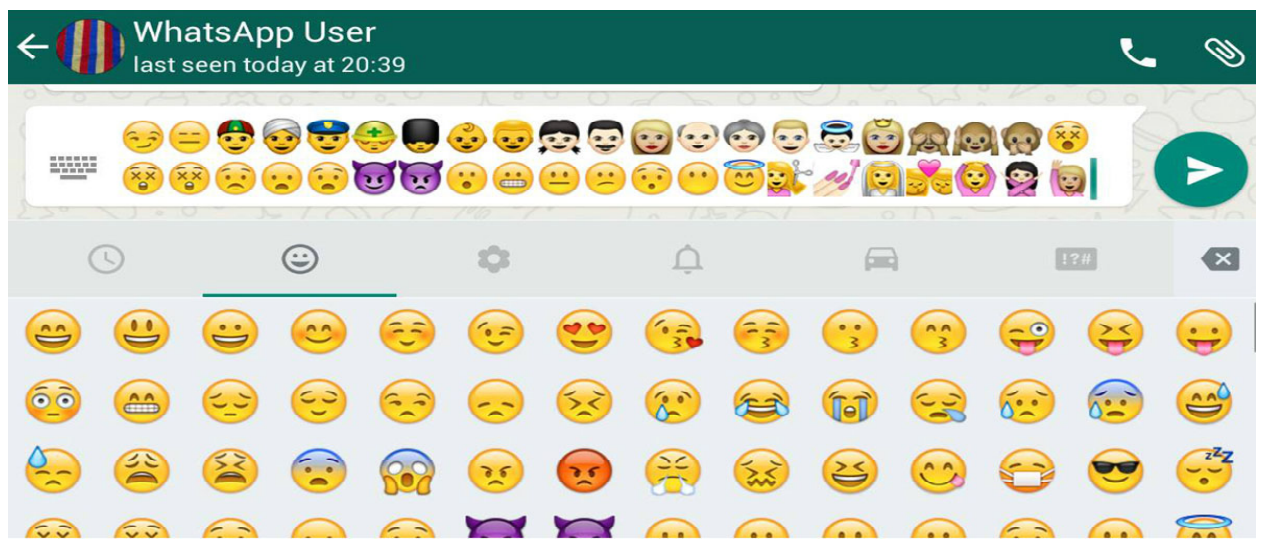

Source: WhatsApp Inc. (2015)

Finally, compared to other text-based communication channels, IM supports the quick and efficient transmission of texts and other types of files such as photos and videos (Church and de Oliveira, 2013; Lancaster et al., 2007). IM by its nature implies instant connection by encouraging people to skip greetings, introductions, and niceties usually required with e-mails and voice and video calls (Kemp et al., 2014). Furthermore, with IM the listener does not have to wait for a slow speaker to get around to his or her point, or manage a talker who speaks for longer than necessary

\subsubsection{Free voice- and video-calls}

In addition to the text based messaging, most IM applications are equipped with free voice- and video-calling features. Free voice- and video-call features allow users to make and receive calls over the Internet, rather than via a landline or traditional mobile network (Yoon et al., 2014). Furthermore, with the Internet connection, users of IM applications at both ends of the communication must have the same IM application installed on their devices (Gan and Li, 2015).

A wide range of free IM applications can be downloaded and installed from application stores such as Play Store, App Store and Windows Phone Store (West and Mace, 2010). Downloading is an easy and quick process that usually takes less than 5 minutes. IM applications are not limited to tablets and mobile devices. Several applications, such as Skype and WhatsApp, provide web-based versions that allow users to install the program on desktops and laptops (Temkar et al., 2015). This feature has many advantageous. For example, users can easily copy and paste information from documents and websites and share it with contacts; using the computer or laptop keyboard is more convenient for many users than using a mobile device's keyboard; users can switch quickly between their office work and chats or calls on computer or laptop; users do not have to worry about the mobile device battery; and, the call quality may be improved, as the user is more likely to have a wired connection to the Internet, which is usually better than wireless or mobile data connections (WhatsApp Inc., 2015).

In general, IM applications can provide a higher quality connection in comparison to landline and traditional cell networks (Prosser, 2015). However, the quality of calls 
through IM applications depends a great deal on the speed of the internet connection (Prosser, 2015). Internet connection speed refers to the number of megabits per second at which data travels from the Internet to the user's device (download), or vice versa (upload) (Salway, 2015). Among the key factors that can affect the internet speed are: the basic speed of the connection provided by the internet service provider (ISP); the range of the Wi-Fi router in the case of using a Wi-Fi connection; and, the type, age, and operating system of the hardware device used for the connection (Vodafone, 2015).

Another significant factor that affects calling quality is the type of IM application used (Triggs, 2015). IM applications offer varying levels of calling quality (Gan and Li, 2015), with the high-definition quality level (HD) offering the highest (Gungl et al., 2014). HD refers to the expansion of the frequency range of audio and/or video signals transmitted over a call, resulting in a high quality call and background noise cancellation (Poynton, 2012). Nevertheless, as Triggs (2015) points out, HD is not always a user's preferred mode of communication due to costs considerations.

Although described as 'free', calls via IM applications are not completely free. Both parties in a call need to have access to the Internet and to consume data ( $\mathrm{Lin}$ and $\mathrm{Li}$, 2014). This arrangement usually involves the payment of a periodical subscription fee as well as additional data consumption ${ }^{2}$-based charges. The average data consumption per minute varies considerably from one application to another. For example, the number of KBs a 1-minute voice call would consume when using Facebook Messenger is 333.3 KBs, compared to 875.0 KBs when using Skype (Triggs, 2015). In addition, data consumption depends on the calling quality level, where higher quality usually implies more data consumption (Deloitte, 2014).

However, regardless of the IM application used and the data quality level, making free calls via IM applications is generally more cost-efficient than making landline or regular phone calls (Deloitte, 2014). The cost of data per minute of call that most IM applications would consume is significantly less than the charge levied by telecom carriers, especially when making international calls (Eldridge, 2014). In addition, unlimited Internet broadband plans are common on most ISPs' modern contracts, which allows users to consume unlimited data without restricting the connection speed or being charged extra fees (Wallsten and Riso, 2014). Furthermore, free Wi-Fi hotspots for wireless Internet access have become widely available around the globe. Many public places such as universities, libraries, coffee shops, parks, hospitals, and airports offer free Wi-Fi hotspots with high Internet connection speeds (Lambert et al., 2014; Strachan, 2014).

\subsection{Social media websites}

The core principle of social media websites such as Facebook and Twitter is the ability to have easy access to others, to share content, and to communicate inexpensively (Langmia et al., 2013). Social media websites allow people to create a user page or profile, and to construct an online network of contacts. Users of these websites can communicate either on a one-to-one basis, or in a more public way, such as a comment or a photo posted for either contacts or anyone else to see (Quan-Haase and Young, 2010).

Along with breadth of global reach (Digital Statshot Report, 2015), social media websites also have many interactive features that heighten their potential to facilitate qualitative research (Quan-Haase and Young, 2010). For example, among the interactive tools that Facebook users may use are buttons such as 'Friend', 'Follow', 'Like', 'Share', 
'Post', 'Comment', and 'Tag'. These tools allow users to initiate, monitor, and join conversations creating a treasure chest full of raw, unprompted, and up-to-date data (Facebook, 2015). The use of social media websites in data collection comes in different forms, such as scraping data from online discussions, mining data from archives, and interviewing online. Moreover, researchers can employ these data to discover trends and identify research opportunities (Lunnay et al., 2015).

Researchers, increasingly, consider using social media websites to communicate, recruit participants, and collect data. The communication nature of social media websites can be highly beneficial for researchers in terms of participant recruitment. For example, it is not usually necessary to know or contact users with public accounts before subscribing to their updates or reviewing their personal profiles (Quan-Haase and Young, 2010). Personal profiles in social media websites contain basic personal and professional information (Zimmer, 2010) such as name, gender, relationships, hometown, work, education, and religious and political views. This feature enables the researcher to review a large number of potential participants' profiles in a short time, making the participant recruitment process easier and more effective (Lunnay et al., 2015).

\section{Criticisms against the face-to-face interview method}

Despite the range of modern online communication options, traditional face-to-face interviews remain dominant (Nandi and Platt, 2016). Traditionalists view face-to-face interviews as a superior data collection instrument compared to telephone or online interviews (e.g., Gillham, 2005; Rubin and Rubin, 1995). However, several studies assess the differential effects of face-to-face and online and telephone interview modes suggest either slight or no effects on data quality (e.g., Jäckle et al., 2006; Shapka et al., 2016). Novick (2008, p.5), though, explains that "there is a need for additional well-designed studies comparing interview modalities in qualitative research. Given the lack of evidence, it is unwarranted to favour any particular interview mode for qualitative interviews".

The review of the literature reveals that critiques of face-to-face interviews are centred around three main issues. First, the cost and time associated with conducting in-person interviews can be high, especially if there is a need to travel long distances to interview participants (Opdenakker, 2006). Traveling to meet interviewees becomes extremely costly and time consuming when conducting research in an area with poor transport infrastructure or bad traffic. This can, in turn, affect the researcher's ability to recruit a representative sample of participants in a timely and cost efficient manner (James and Busher, 2009).

Second, limited geographical access due to factors other than cost, such as access to politically sensitive areas, war zones, military sites, or regions posing a risk to the researcher's health (Gubrium and Holstein, 2002; Mosley, 2013). Multiple authorisations, from governments, ethics committees and/or private institutions are usually required for travel, or access, to such risky areas or sites. Such authorisations can be hard to gain due to political, security, health or ethical considerations (Wood, 2006).

Third, the unsuitability of the face-to-face contact when researching sensitive topics. Sturges and Hanrahan (2004) argue that respondents being interviewed about sensitive topics, such as sexual experience, drug abuse or incidents of dishonesty, may feel uncomfortable being interviewed personally, and thus may not respond accurately. 
McCosker et al. (2001) explain that potential risk associated with sensitive research may impact several participants such as the interviewer, interviewee, supervisor, and reader. This risk may be physical and/or psychological. Failing to consider, and protect, the physical and psychological safety of all participants involved in the research can impact negatively their objectivity and, therefore, the data validity.

\section{Discussion and reflection on conducting interviews in Jordan}

People's habits, perceptions, and preferences regarding communication channels vary considerably (Donner, 2008; Jerzy, 2008). Many people perceive voice calls as more suited for urgent matters, or for personal communication with family and close friends (Ling and Campbell, 2011). Others even consider a phone call, without prior arrangement through an e-mail or a text message, as an interruption or as impolite (Toninelli et al., 2008). In contrast, IM is usually perceived as a user-friendly communication channel that is more readily used by anybody, and for a variety of purposes.

Time is a central component of culture and communication (Hofstede, 1980). Each culture has its own perception of time (Samovar et al., 2012). Different interpretations of punctuality, meeting deadlines, and the 'best use' of time are some aspects of how time can be perceived differently across cultures (Macduff, 2006). These perceptions of time are determined by cultural, religious, social, and economic factors. Understanding people's time orientations can help researchers to overcome some of the potential communication challenges they face when doing qualitative research.

Trompenaars and Hampden-Turner (1997) distinguish cultural perceptions of time as either sequential or synchronic. In sequential cultures, such as in the USA and the UK, people tend to concentrate on one activity or project at a time, and place a high value on following schedules and plans, and meeting deadlines. In contrast, the followers of synchronic cultures, such as those found in the Middle East, including Jordan, prefer to work on several activities or projects at once, and consider plans and deadlines as flexible and appointment times as approximate.

Social networks have grown rapidly in the Arab world over the last ten years, becoming more of a fixed presence in the people lives (Coulson, 2013). Likewise, a rise in social networks usage in Jordan followed a rise in overall internet and smartphones 3 penetration. According to the Pew Global Attitudes Survey, 47\% of Jordanians have access to the internet, $97 \%$ own mobile phones, and $41 \%$ of mobile holders have smartphones (Pew Research Center, 2014). In the following subsections, we explain how our understanding of the cultural values and characteristics and the progress toward social media in Jordan have been considered and utilised through this research.

\subsection{Selecting and accessing participants}

Qualitative research may rely on strategies of purposeful sampling, or the selection of participants who can best enrich understanding of the phenomenon under study (Marshall, 1996). Decisions regarding selection of participants therefore requires significant attention and should be consistent with the research purposes and questions, theoretical paradigms, and evidence informing the study (Coyne, 1997; Seidman, 2013).

Participants in this study were selected on the basis of two, complementary sampling techniques, namely, purposive sampling (Ritchie et al., 2014) and snowball sampling 
(Noy, 2008). In purposive sampling, participant selection is based on a predetermined set of criteria such as personal characteristics and attributes, scientific degrees or certificates, and particular knowledge or experience (Merriam and Tisdell, 2009). This study's participants included: practitioners from private audit firms, public control agencies and large firms and banks in Jordan; academics from schools of business and law; lawyers and legal experts; decision makers for the Jordanian Association of Certified Public Accountants and the Higher Education Accreditation Commission; and, Islamic theologians.

Snowball sampling is a technique where existing participants direct the researcher towards others who meet the study's criteria (Biernacki and Waldorf, 1981). In this study, snowball sampling was applied in two ways. One way was that participants nominated other people to be contacted, and after obtaining their permission passed on their contact details to the researcher. In the second case, participants recommended organisations to contact, without identifying a particular contact within the organisation, due to the knowledge base of the organisation identified. Atkinson and Flint (2001) claim that snowball sampling makes the data collection process into more of an investigation, where the interview of one person leads to another, forming a more comprehensive picture for the topic under study.

This study involved semi-structured interviews with 40 individuals. Twenty-five of the interviews were undertaken using the voice mode, and 15 using the video mode. Most of the interviews lasted between 45 minutes and 1 hour, with an average time of 55 minutes. Participants were always given the option to decide whether they would prefer a voice or video interview. Only 15 participants preferred video over voice interviews, although social platforms with a video call feature and reliable Internet connections that support video calls were available for at least 30 participants. Most interviews were conducted through free phone and video calls. However, international call costs had to be absorbed by the researchers when participants preferred to use landlines. A range of social media, such as Facebook, Twitter, LinkedIn, Skype, WhatsApp, and Viber, were used to recruit and contact participants.

Skype interviews were recorded using software that saves and records directly to the PC (Amolto Call Recorder, 2015). All the other interviews were recorded using either a smartphone or a built-in PC sound recorder. All were conducted in complete privacy; to protect the identity of the interviewees.

The interviews were semi-structured, utilising a flexible interview guide to meet participants needs (Ritchie et al., 2005; Clifford et al., 2010). The questions asked ranged from questions about the demand for and supply of forensic accountants in Jordan, to potential advantages and disadvantages of and barriers to teaching forensic accounting, to which cultural and contextual requirements should be taken into account in relation to forensic accounting practice and education. Answers to the optimal structure, content, learning resources, materials, and assessment methods for a forensic accounting curriculum were also sought. Each interview commenced with putting participant at ease (Miles and Gilbert, 2005). The sequence of the interview questions, the way particular areas might be followed up, and the tone or terminology used in discussion varied across interviews depending on a participant's answers (Clifford et al., 2010). For example, if the participant began the interview by talking about the culture and business environment in Jordan, the interviewer would skip ahead to related questions as appropriate. Remaining questions in the interview guide would be asked as and when they fitted the 
discussion. Interviewees were provided with an opportunity at the end to add any additional information.

\subsubsection{Jordanian culture and communication choice}

As identified by Kim et al. (2008) and Suki et al. (2011), the majority of the interviewees in this study preferred instant interactive conversations and thus preferred IM as a communication channel. IM was useful in situations where it was difficult to predict how a participant would respond to a voice call. IM is less intrusive than a voice or a video conversation, especially for the first contact, because it allows the receiver to identify the sender, read the message, and, then, decide how and when to respond.

IM proved to be an effective communication channel through which it was possible to provide potential participants with further information and provided the ability to interviewers to respond to any questions. As noted by Kemp et al. (2014), people tend to correspond over IM in terms of a quick, informal, and brief chat. The use of IM also provided potential interviewees with easy access to the interviewer regarding their concerns and questions. IM also allowed the interviewer to respond and to provide explanations in a simple and friendly manner. Given that the participants in the research were mainly academics, auditors, and upper level executives, often too busy to answer a phone call or even respond to an e-mail, using IM to access them created ease and convenience.

Ritchie et al. (2014) identified the merits of achieving a successful first contact with potential participants. In addition to briefly introducing the researcher, first impressions had to be managed while also establishing a trusting relationship with the participant. After this initial level of trust was established a more detailed discussion could take place regarding: the purpose of the research and the interview; terms of confidentiality; length of time the interview would likely take; participant choice of interview mode (either video or voice); communication channel to be used for conducting the interview; and a suitable interview time.

Achieving a successful first contact was challenging for two main reasons. The first was that Jordanians perceive e-mail communication as a lower priority. This perception is indicated by the low response rate to the e-mail invitation, compared to the responses received when they were followed up with phone calls to non-respondents. In the first month of data collection, 20 letters of invitation were sent via e-mail; however, only four responses were received. Even when initial invitations were followed up with a reminder e-mail, a phone call, or both, the response rate did not improve significantly. Responses in follow-up phone calls were: "I have not checked my email account this week"; "Your email may be marked as spam by mistake, I will double check"; "I have received your email, but I have not got a chance to open it yet"; "I have received your email but I cannot find it now; send it again please"; and, "I do not check my email address regularly, how can I help please?". In a number of cases, the e-mail invitation was sent more than three times with no effect. The challenge presented by a non-response reaction to e-mail invitation was significant and indicated that a different strategy would be required. To overcome the identified challenge, communication channel preferences of each potential participant had to be understood. Facebook as a form of social media utilised to search for the accounts of interviewees who had not responded to e-mails. The majority of potential interviewees had public accounts on Facebook, which enabled checking their personal and professional details and updates without directly contacting 
them (Mathiyalakan et al., 2013). Four potential participants were sent 'friend requests' along with an initial invitation message and three of these 'accepted' the 'friend requests' and replied to messages in less than 12 hours. The results obtained using other social media such as WhatsApp and Viber were equally successful.

The nature of the research topic (perceived by interviewees as complex), address of origin of the interviewer (a knowledgeable expert from a Western university) also presented challenges. At first glance, some participants had reservations about their confidence and competence to participate in the study. This reticence is best exemplified by the following response from $\mathrm{Hamza}^{4}$, an audit manager:

"I do not have an academic knowledge in forensic accounting; I just have practical experience...you are doing your $\mathrm{PhD}$ in forensic accounting in a Western university and I am sure you know much about this field...I don't know if I will be able to provide you with valuable information!"

After Hamza was provided with further information about the research addressing his concerns, and clarifying how sharing his professional experience could enrich the research, Hamza's reluctance to participate turned into enthusiasm.

The purpose of providing participants with rich detail was to ensure that each potential participant would obtain sufficient, clear, brief information on the research, while taking each individual's differences, preferences, and background into account. The significance of this strategy was underscored when two potential participants provided with identical information in terms of form and content, responded with contradictory feedback. One participant indicated that information provided was 'short' and required more information to get a 'clear understanding' of the research topic. The other asked for 'more brief' information that would allow him to get 'a clear picture' of research. Both participants were provided with further information tailored to their individual requirements, this resulted in rich discussions in which the participants were able to give precise and detailed answers to questions asked in the interview.

Reviewing participants' personal profiles and updates in social media websites also allowed the researchers to capture and consider participants' personalities and preferences when approaching them. This approach was effective and helped to build trust, rapport, and friendly communication. An example of a conversation, with a finance manager - Hasan, is provided in Figure 2. Taking into account that Hasan was interested in music, an interest identified via hos Facebook profile, one of the researchers reminded him about a scheduled meeting using the lyrics of one of his favourite songs. This reminder was short and friendly, and Hasan response was prompt and positive.

When conducting the research interviews, a few participants rescheduled at the last minute or showed up late, or missed an agreed appointment. However, using social media provided flexibility in scheduling and rescheduling interviews. Neither the interviewer nor the interviewee had to leave their office or home in order to conduct the interview; nor did either need to be concerned about the waste of time and money that usually ensues when cancelling interviews. In addition, IM allowed the interviewer to send quick reminders, receive instant confirmations or apologies, and reschedule interviews easily and immediately. An example can be seen in one of the author's correspondence with Ammar.

Author: I sent you a contact request on Skype, could you accept please? I will call you in 5 minutes if that still suits you?

Ammar: Just give me 15 minutes please to get home. 
About an hour later, Ammar sent an instant message saying:

Ammar: I am sorry, could we have our conversation tomorrow please? I have an urgent work. Tomorrow morning I will contact you to arrange.

Ammar mentioned only an approximate time for the interview, preferring to leave the exact time on the following day open and allowing him to make contact either a few hours or even a few minutes before the interview. As a busy chief auditor, Ammar was perhaps concerned he would again not be able to take the time to be interviewed as scheduled, so he wanted to ensure that he was free from any commitments before rescheduling the interview. Being able to communicate via IM was convenient for Ammar and allowed for more precision in rescheduling the interview.

Figure 2 A conversation between one of the researchers and a participant (see online version for colours)
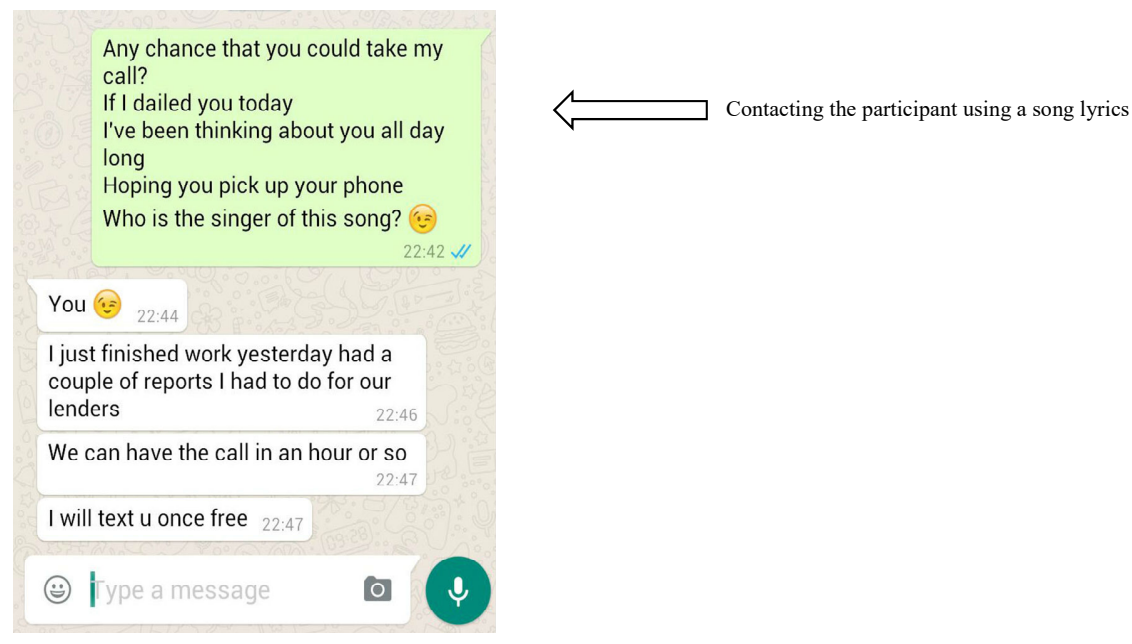

Source: Original

\subsection{The interviews process}

Conducting most of the interviews online through free calls and video conferencing facilitated a successful recruitment of research participants and led to rich and thorough interviews. Many participants expressed gratitude for giving them the opportunity to be interviewed through modern communication channels. The possibility of being interviewed online or over the phone was attractive to many participants who would not have had the time or the possibility to participate in an in-person interview. For example, for Yasin, who works two hours away from home, being able to be interviewed via Skype meant that he did not need to meet the interviewer after a long working day and then arrive home late at night. Yasin clarified that it would be impossible for him either to meet during his working hours or lunch time. "I live in Al-Mafraq and work in Amman, if the interview was not via Skype I would not be able to participate."

The use of video-calling technologies in conducting qualitative interviews is expanding and allowing for higher quality interviews (Sullivan, 2013). Social media allow researchers to conduct video interviews with individuals and to hold small focus 
groups. As with in-person interviews, video interviews provided high information richness, as they allowed the interviewer and interviewee to observe non-verbal cues (Sullivan, 2013). The cost of video interviews was significantly less than in-person interviews (Markham, 2005).

Voluntary participation in research detracts from already precious leisure-time and social life. Employees in Jordan spend long hours at work, working nearly 50 hours per week (Department of Statistics, 2015). As a result, they have less time available to spend on social and leisure activities (OECD Better Life Index, 2015). The participants in this study appreciated the fact that they could participate at a time of the day or night that was most convenient for them, and without having to worry about finding a suitable venue to meet.

Conducting online interviews allowed for in-depth and full discussions, because the participants were being interviewed in familiar and comfortable settings. A skype interview conducted with Ibrahim, a finance manager and academic, serves as an example. The interviewer noticed Ibrahim was sitting on the floor, leaning against a couch, and holding a huge cup of coffee and clarified "Good that you are conducting online interviews, as I am usually busy until late night with work and social visits. I just got my children down for sleep...so I am free now to discuss whatever you want." The in-depth discussion with Ibrahim lasted well beyond the time frame originally planned.

Using social media to conduct online interviews also enabled interviews with participants who the interviewer would never have been able to access via in-person interviews. The researchers were able to conduct interviews with Jordanian participants located in more than five countries, Jordan, Qatar, Kuwait, the United Arab Emirates, and Saudi Arabia, which was necessary as 500,000 Jordanians (one third of the Jordanian domestic labour force) work abroad (Comolet, 2014). In order to generate rich data it was necessary to also represent the number and level of Jordanians working abroad by including them in the interview process.

IM also overcomes one of the challenges of keeping or taking notes of people contacted and responses as it provides digital historical records of conversations (Schwarz, 2011). This decreases the risk of data loss, as the history of conversations, contacts, and media could be backed up and resaved. Several applications and Cloud storage services also provided the researchers with the benefit of easily accessible and searchable data.

Many IM applications such as Skype and WhatsApp support more than one communication mode simultaneously. For example, users can exchange and view texts, emoticons, and photos during a video or voice chat. This 'multitasking' feature is useful in cases where texts, documents, and, websites' links had to be exchanged with participants for discussion purposes.

\section{Conclusions}

The aim of this study was to assist researchers, particularly those conducting qualitative audit research, to determine how they would benefit from using social media, and to guide them in the selection and use of social media channels. This study explored how social media was effectively used when the interviews were conducted for an audit research project. The findings of this study emphasise the increasing importance of social media channels and provide insight into accessing participants and conducting interviews 
using social media. This study therefore makes a practical contribution to researchers wanting to progress from traditional communication channels toward social media in conducting qualitative research.

\section{References}

Acar, A. (2008) 'Antecedents and consequences of online social networking behavior: the case of Facebook', Journal of Website Promotion, Vol. 3, Nos. 1-2, pp.62-83, DOI: $10.1080 / 15533610802052654$.

Alabdullah, T., Alfadhl, M., Yahya, S. and Rabi, A. (2014) 'The role of forensic accounting in reducing financial corruption: a study in Iraq', International Journal of Business Management, Vol. 9, No. 1, pp.26-34, DOI: 10.5539/ijbm.v9n1p26.

Amolto Call Recorder (2015) Amolto Call Recorder for Skype - Call Recording for Skype [online] http://amolto.com (accessed 9 October 2015).

Atkinson, R.G. and Flint, J. (2001) 'Accessing hidden and hard-to-reach populations: snowball research strategies', Social Research Update, Summer, Vol. 33.

Ayres, E.J. (2013) 'The impact of social media on business and ethical practices in dietetics', Journal of the Academy of Nutrition and Dietetics, Vol. 113, No. 11, pp.1539-1543, https://doi.org/10.1016/j.jand.2013.09.020.

Belew, S. (2014) The Art of Social Selling: Finding and Engaging Customers on Twitter, Facebook, LinkedIn, and Other Social Networks, American Management Association, New York [online] http://site.ebrary.com/lib/waikato/Top?id=10816210 (accessed 1 September 2015).

Biernacki, P. and Waldorf, D. (1981) 'Snowball sampling: problems and techniques of chain referral sampling', Sociological Methods \& Research, Vol. 10, No. 2, pp.141-163, https://doi.org/10.1177/004912418101000205.

Brislin, R.W. (1980) 'Translation and content analysis of oral and written material', Handbook of Cross-Cultural Psychology, Vol. 2, No. 2, pp.349-444.

Bronner, F. and de Hoog, R. (2014) 'Social media and consumer choice', International Journal of Market Research, Vol. 56, No. 1, pp.51-71, https://doi.org/10.2501/IJMR-2013-053.

Buchenscheit, A., Könings, B., Neubert, A., Schaub, F., Schneider, M. and Kargl, F. (2014) 'Privacy implications of presence sharing in mobile messaging applications', in Proceedings of the 13th International Conference on Mobile and Ubiquitous Multimedia, pp.20-29, ACM, New York, NY, USA, https://doi.org/10.1145/2677972.2677980.

Carr, E.C.J. and Worth, A. (2001) 'The use of the telephone interview for research', Nursing Times Research, Vol. 6, No. 1, pp.511-524, https://doi.org/10.1177/136140960100600107.

Church, K. and de Oliveira, R. (2013) 'What's up with Whatsapp?: Comparing mobile instant messaging behaviors with traditional SMS', in Proceedings of the 15th International Conference on Human-computer Interaction with Mobile Devices and Services, pp.352-361, ACM, New York, NY, USA, https://doi.org/10.1145/2493190.2493225.

Clifford, N., French, S. and Valentine, G. (2010) Key Methods in Geography, SAGE, London, UK.

Comolet, E. (2014) Jordan: The Geopolitical Service Provider, Global Economy and Development [online] http://www.brookings.edu/ /media/research/files/papers/2014/02/jordan-geopolticalservice-provider-comolet/arab-econpaper4comolet-v2.pdf (accessed 1 September 2015).

Coulson, D.C. (2013) 'Dynamics of social media, politics and public policy in the Arab World', Global Media Journal, Vol. 12, No. 22, pp.1-20.

Coyne, I.T. (1997) 'Sampling in qualitative research. Purposeful and theoretical sampling; merging or clear boundaries?', Journal of Advanced Nursing, Vol. 26, No. 3, pp.623-630.

Deloitte (2014) Mobile Messaging Market Watch: MIM vs. SMS, 28 April [online] http://deloitte.wsj.com/cio/2014/04/28/mobile-messaging-market-watch-mim-vs-sms/ (accessed 7 October 2015). 
Department of Statistics (2015) DataBase Online [online] http://jorinfo.dos.gov.jo/ PXWeb2014R2/Selection.aspx?px_tableid=EMP35\&px_path=START_02_0207\&px language $=$ en\&px_db=DOS\%20Database\&rxid=e0c35eac-d04f-4689-ace3-8f29bflf19da (accessed 1 September 2015).

Digital Statshot Report (2015) Digital, Social \& Mobile Worldwide in 2015 [online] http://wearesocial.net/blog/2015/01/digital-social-mobile-worldwide-2015/ (accessed 1 September 2015).

Donner, J. (2008) 'Research approaches to mobile use in the developing world: a review of the literature', The Information Society, Vol. 24, No. 3, pp.140-159, https://doi.org/10.1080/ 01972240802019970.

Eldridge, A. (2014) Replace Phone Carriers with Apps, 31 March [online] http://callnerds.com/ replace-phone-carriers-with-apps/ (accessed 12 October 2015).

Elitas, C., Karakoç, M. and Görgülü, M.E. (2011) 'Stance of accounting instructors to forensic accountancy profession: example of Turkey', International Journal of Business and Social Science, Vol. 2, No. 10, pp.224-241.

Elsbach, K.D. and Bechky, B.A. (2009) Qualitative Organizational Research: Best Papers from the Davis Conference on Qualitative Research, IAP.

Facebook (2015) Facebook Help Center | Facebook [online] https://www.facebook.com/help/ (accessed 9 October 2015).

Filep, B. (2009) 'Interview and translation strategies: coping with multilingual settings and data', Social Geography, Vol. 4, No. 1, pp.59-70, https://doi.org/10.5194/sg-4-59-2009.

Gan, C. and Li, H. (2015) 'Understanding continuance intention of mobile instant messaging: motivators and inhibitors', Industrial Management \& Data Systems, Vol. 115, No. 4, pp.646-660, https://doi.org/10.1108/IMDS-11-2014-0331.

Garrett, R.K. and Danziger, J.N. (2007) 'IM = interruption management? Instant messaging and disruption in the workplace', Journal of Computer-Mediated Communication, Vol. 13, No. 1, pp.23-42, https://doi.org/10.1111/j.1083-6101.2007.00384.x.

Gillham, B. (2005) Research Interviewing: The Range of Techniques: A Practical Guide, McGraw-Hill Education, UK [online] https://books.google.co.nz/books?hl=en\&lr=\&id= fU_oAAAAQBAJ\&oi=fnd\&pg=PP1\&dq=Research+Interviewing:+The+Range+of + Techniques\&ots=BQycmZHYgg\&sig=e5YJOM-N0zy05Xma29seJQcX51Q (accessed 1 September 2015).

GlobalWebIndex (2014) Digital vs Traditional Media Consumption [online] http://insight.globalwebindex.net/hs-fs/hub/304927/file-1414878665pdf/Reports/GWI_Media_Consumption_Summary_Q3_2014.pdf (accessed 1 September 2015).

Google Trends (2015) Google Trends - Web Search Interest - Worldwide, 2004 - Present [online] https://www.google.co.nz/trends/explore\#q=social\%20media\%2C\%20social\%20network\&cm $\mathrm{pt}=\mathrm{q} \& \mathrm{tz}=\mathrm{Etc} \% 2 \mathrm{FGMT}-13$ (accessed 5 October 2015).

Groves, R.M. (1990) 'Theories and methods of telephone surveys', Annual Review of Sociology, pp.221-240, (accessed 1 September 2015).

Gubrium, J.F. and Holstein, J.A. (2002) Handbook of Interview Research: Context and Method, SAGE, Thousand Oaks, CA.

Gungl, J., Gratzer, A., Ruhle, E-O. and Fruend, N. (2014) Telecommunications: Applications, Modern Technologies and Economic Impact, Novinka, New York [online] http://site.ebrary.com/lib/waikato/Top?id=10849476.

Gustafson, D.L. and Woodworth, C.F. (2014) 'Methodological and ethical issues in research using social media: a metamethod of Human Papillomavirus vaccine studies', BMC Medical Research Methodology, Vol. 14, p.127, https://doi.org/http://dx.doi.org.ezproxy.waikato.ac. $\mathrm{nz} / 10.1186 / 1471-2288-14-127$.

Hao, X. (2010) 'Analysis of the necessity to develop the forensic accounting in China', International Journal of Business and Management, Vol. 5, No. 5, pp.185-187. 
Herzog, A.R. and Rodgers, W.L. (1988) 'Interviewing older adults: mode comparison using data from a face-to-face survey and a telephone resurvey', The Public Opinion Quarterly, Vol. 52, No. 1, pp.84-99.

Hofstede, G.H. (1980) Culture's Consequences: International Differences in Work-Related Values, Sage Publications, Beverly Hills, Calif.

Hsieh, S.H. and Tseng, T.H. (2015) The Effects of Emoticons and Text-Messaging on Social Interaction: Playfulness in Mobile Instant Messaging [online] http://pacis2015.comp.nus.edu. sg/_proceedings/PACIS_2015_submission_116.pdf (accessed 1 September 2015).

Huber, W.D. (2012) Is Forensic Accounting in the United States Becoming a Profession?, SSRN Scholarly Paper No. ID 2041755, Social Science Research Network, Rochester, NY [online] http://papers.ssrn.com/abstract=2041755 (accessed 1 September 2015).

Jäckle, A., Roberts, C. and Lynn, P. (2006) Telephone Versus Face-to-Face Interviewing: Mode Effects on Data Quality and Likely Causes: Report on Phase II of the ESS-Gallup Mixed Mode Methodology Project, Institute for Social and Economic Research [online] http://econpapers.repec.org/paper/eseiserwp/2006-41.htm (accessed 1 September 2015).

James, N. and Busher, H. (2009) Online Interviewing, SAGE Publications Ltd., 1 Oliver's Yard, 55 City Road, London EC1Y 1SP [online] http://methods.sagepub.com/book/online-interviewing (accessed 1 September 2015).

Jerzy, K. (2008) Virtual Technologies: Concepts, Methodologies, Tools, and Applications: Concepts, Methodologies, Tools, and Applications, IGI Global, Warsaw, Poland.

Jibril, T.A. and Abdullah, M.H. (2013) 'Relevance of emoticons in computer-mediated communication contexts: an overview', Asian Social Science, Vol. 9, No. 4, pp.201-207.

Kaplan, A.M. and Haenlein, M. (2010) 'Users of the world, unite! The challenges and opportunities of social media', Business Horizons, Vol. 53, No. 1, pp.59-68, https://doi.org/10.1016/ j.bushor.2009.09.003.

Kemp, N., Wood, C. and Waldron, S. (2014) 'Do I know its wrong: children's and adults' use of unconventional grammar in text messaging', Reading and Writing, Vol. 27, No. 9, pp.1585-1602, https://doi.org/http://dx.doi.org.ezproxy.waikato.ac.nz/10.1007/s11145-0149508-1.

Kent, M. and Leaver, T. (Eds.) (2014) An Education in Facebook? Higher Education and the World's Largest Social Network, Routledge, New York [online] http://site.ebrary.com/lib/ waikato/Top?id=10896014 (accessed 1 September 2015).

Kim, G.S., Park, S-B. and Oh, J. (2008) 'An examination of factors influencing consumer adoption of short message service (SMS)', Psychology and Marketing, Vol. 25, No. 8, pp.769-786, https://doi.org/10.1002/mar.20238.

Kvale, S. and Brinkmann, S. (2009) InterViews: Learning the Craft of Qualitative Research Interviewing, 2nd ed., Sage Publications, Los Angeles.

Lambert, A., McQuire, S. and Papastergiadis, N. (2014) 'Public Wi-Fi: space, sociality and the social good', Australian Journal of Telecommunications and the Digital Economy, Vol. 2, No. 3, p.45.

Lancaster, S., Yen, D.C., Huang, A.H. and Hung, S-Y. (2007) 'The selection of instant messaging or e-mail: college students' perspective for computer communication', Information Management \& Computer Security, Vol. 15, No. 1, pp.5-22, https://doi.org/10.1108/ 09685220710738750 .

Langmia, K., Tyree, T., O’Brien, P. and Sturgis, I. (2013) Social Media: Pedagogy and Practice, University Press of America, Lanham, MD.

Lee, S., Wong, Y-L.I. and Rothbard, A. (2014) 'Effects of social networks on physical health among people with serious mental illness', Psychiatric Quarterly, Vol. 85, No. 4, pp.453-465, https://doi.org/10.1007/s11126-014-9306-6.

Lin, T.T. and Li, L. (2014) 'Perceived characteristics, perceived popularity, and playfulness: youth adoption of mobile instant messaging in China', China Media Research, Vol. 10, No. 2, pp.60-71. 
Ling, R.S. and Campbell, S.W. (2011) Mobile Communication: Bringing Us Together and Tearing Us Apart, Transaction Publishers, New Brunswick, NJ.

Lunnay, B., Borlagdan, J., McNaughton, D. and Ward, P. (2015) 'Ethical use of social media to facilitate qualitative research', Qualitative Health Research, Vol. 25, No. 1, pp.99-109, https://doi.org/10.1177/1049732314549031.

Macduff, I. (2006) 'Your pace or mine? Culture, time, and negotiation', Negotiation Journal, Vol. 22, No. 1, pp.31-45.

Mahan III, J.E., Seo, W.J., Jordan, J.S. and Funk, D. (2015) 'Exploring the impact of social networking sites on running involvement, running behavior, and social life satisfaction', Sport Management Review, Vol. 18, No. 2, pp.182-192, https://doi.org/10.1016/j.smr.2014.02.006.

Mangold, W.G. and Faulds, D.J. (2009) 'Social media: the new hybrid element of the promotion mix', Business Horizons, Vol. 52, No. 4, pp.357-365, https://doi.org/10.1016/ j.bushor.2009.03.002.

Mano, R.S. (2014) 'Social media, social causes, giving behavior and money contributions', Computers in Human Behavior, Vol. 31, pp.287-293, https://doi.org/10.1016/j.chb.2013. 10.044 .

Markham, A.N. (2005) 'The methods, politics, and ethics of representation in online ethnography', in The Sage Handbook of Qualitative Research, SAGE, Thousand Oaks, CA, Citeseer [online] http://citeseerx.ist.psu.edu/viewdoc/summary?doi=10.1.1.508.444.

Marshall, M.N. (1996) 'Sampling for qualitative research', Family Practice, Vol. 13, No. 6, pp.522-526, https://doi.org/10.1093/fampra/13.6.522.

Mathiyalakan, S., Heilman, G., and White, S. (2013) 'Gender differences in student attitude toward privacy in Facebook', Communications of the IIMA, Vol. 13, No. 4, pp.35-42.

McCosker, H., Barnard, A. and Gerber, R. (2001) 'Undertaking sensitive research: issues and strategies for meeting the safety needs of all participants', Forum Qualitative Sozialforschung/Forum: Qualitative Social Research, Vol. 2, No. 1 [online] http://www.qualitative-research.net/index.php/fqs/article/view/983 (accessed 1 September 2015).

Merriam, S.B. and Tisdell, E.J. (2009) Qualitative Research: A Guide to Design and Implementation, Jossey-Bass, San Francisco [online] http://site.ebrary.com/lib/waikato/ Top?id=10856838 (accessed 1 September 2015).

Miles, J. and Gilbert, P. (2005) A Handbook of Research Methods for Clinical and Health Psychology, Oxford University Press, Oxford, England.

Mosley, L. (2013) Interview Research in Political Science, Cornell University Press, Ithaca, NY.

Nandi, A. and Platt, L. (2016) 'Are there differences in responses to social identity questions in face-to-face versus telephone interviews? Results of an experiment on a longitudinal survey', International Journal of Social Research Methodology, pp.1-16, https://doi.org/10.1080/ 13645579.2016 .1165495$.

Novick, G. (2008) 'Is there a bias against telephone interviews in qualitative research?', Research in Nursing \& Health, Vol. 31, No. 4, pp.391-398, https://doi.org/10.1002/nur.20259.

Noy, C. (2008) 'Sampling knowledge: the hermeneutics of snowball sampling in qualitative research', International Journal of Social Research Methodology, Vol. 11, No. 4, pp.327-344, https://doi.org/10.1080/13645570701401305.

OECD Better Life Index (2015) OECD Better Life Index [online] about:reader?url=http\%3A\%2F\%2Fwww.oecdbetterlifeindex.org\%2Ftopics\%2Fwork-lifebalance $\% 2 \mathrm{~F}$ (accessed 3 October 2015).

Opdenakker, R. (2006) 'Advantages and disadvantages of four interview techniques in qualitative research', in Forum Qualitative Sozialforschung/Forum: Qualitative Social Research, Vol. 7 [online] http://www.qualitative-research.net/index.php/fqs/article/viewArticle/175 (accessed 1 September 2015).

Oxford Dictionaries (2015a) Smartphone [online] http://www.oxforddictionaries.com/definition/ english/smartphone (accessed 1 September 2015). 
Oxford Dictionaries (2015b) Social Media [online] http://www.oxforddictionaries.com/definition/ english/social-media (accessed 1 September 2015).

Oxford Dictionaries (2015c) Social Networking [online] http://www.oxforddictionaries.com/ definition/english/social-networking\#social-networking_3 (accessed 1 September 2015).

Parsons, K. and Woolley, A.B. (2013) 'Use of an instant messaging application to facilitate pharmacy students' learning during medical rounds', American Journal of Health-System Pharmacy, Vol. 70, No. 19, pp.1654-1655, https://doi.org/10.2146/ajhp130294.

Patton, M.Q. (1990) Qualitative Evaluation and Research Methods, SAGE Publications, Inc. [online] http://psycnet.apa.org/psycinfo/1990-97369-000 (accessed 1 September 2015).

Peslak, A., Ceccucci, W. and Sendall, P. (2010) 'An empirical study of instant messaging (IM) behavior using theory of reasoned action', Journal of Behavioral and Applied Management, Vol. 11, No. 3, pp.263-278.

Pew Research Center (2014) Emerging Nations Embrace Internet, Mobile Technology [online] http://www.pewglobal.org/2015/03/19/internet-seen-as-positive-influence-on-education-butnegative-influence-on-morality-in-emerging-and-developing-nations/ (accessed 1 September 2015).

Poynton, C. (2012) Digital Video and HD: Algorithms and Interfaces, 2nd ed., Elsevier, Waltham, MA.

Prosser, M. (2015) Small Business Phone System: VoIP or Traditional Landline?, 15 September [online] http://fitsmallbusiness.com/small-business-phone-system/ (accessed 7 October 2015).

Quan-Haase, A. and Young, A.L. (2010) 'Uses and gratifications of social media: a comparison of Facebook and instant messaging', Bulletin of Science, Technology \& Society, Vol. 30, No. 5, pp.350-361, https://doi.org/10.1177/0270467610380009.

Ritchie, B.W., Burns, P. and Palmer, C. (2005) Tourism Research Methods: Integrating Theory with Practice, CABI, Wallingford, England.

Ritchie, J., Lewis, J., McNaughton Nicholls, C. and Ormston, R. (Eds.) (2014) Qualitative Research Practice: A Guide for Social Science Students and Researchers, 2nd ed., SAGE, Los Angeles, California.

Rosenbaum, M. and Wong, I.A. (2012) 'The effect of instant messaging services on society's mental health', Journal of Services Marketing, Vol. 26, No. 2, pp.124-136, https://doi.org/10.1108/08876041211215284.

Rubin, H.J. and Rubin, I. (1995) Qualitative Interviewing: The Art of Hearing Data, Sage Publications, Thousand Oaks.

Salway, D. (2015) How Much Speed Do You Need? A Thorough Explanation of Broadband Internet Speeds [online] http://broadband.about.com/od/speedissues/a/Broadband-InternetSpeeds-Explained.htm (accessed 7 October 2015).

Samovar, L., Porter, R., McDaniel, E. and Roy, C. (2012) Communication between Cultures, Cengage Learning, Boston, MA.

Schwarz, O. (2011) 'Who moved my conversation? Instant messaging, intertextuality and new regimes of intimacy and truth', Media, Culture \& Society, Vol. 33, No. 1, pp.71-87, https://doi.org/10.1177/0163443710385501.

Seidman, I. (2013) Interviewing as Qualitative Research: A Guide for Researchers in Education and the Social Sciences, Teachers College Press, New York, NY.

Shanikat, M. and Khan, A. (2013) 'Culture-specific forensic accounting conceptual framework: a skills set theoretical analysis', International Journal of Business and Management, Vol. 8, No. 15, pp.112-123, DOI: 10.5539/ijbm.v8n15p112.

Shapka, J.D., Domene, J.F., Khan, S. and Yang, L.M. (2016) 'Online versus in-person interviews with adolescents: an exploration of data equivalence', Computers in Human Behavior, Vol. 58, pp.361-367, https://doi.org/10.1016/j.chb.2016.01.016.

Shuy, R.W. (2003) 'In-person versus telephone interviewing', Inside Interviewing: New Lenses, New Concerns, pp.175-193, Sage, Thousand Oaks, CA. 
Siegel, J.G. and Shim, J.K. (2010) Accounting Handbook, 5th ed., Barron's Educational Series, Hauppauge, NY.

Skovholt, K., Gronning, A. and Kankaanranta, A. (2014) 'The communicative functions of emoticons in workplace e-mails: :-)', Journal of Computer-Mediated Communication, Vol. 19, No. 4, pp.780-797, https://doi.org/10.1111/jcc4.12063.

Social Compare (2015) Compare Instant Messengers (IM) with Phone, Mobile and Video Calls Options [online] http://socialcompare.com/en/comparison/online-web-chat-messenger-talksystems-free-skype-vs-viber (accessed 5 October 2015).

Statista (2015) Social Networks [online] http://www.statista.com/topics/1164/social-networks/ (accessed 1 October 2015).

Strachan, D. (2014) Free Wi-Fi Networks: The World's Most Connected Cities, 29 April [online] http://www.telegraph.co.uk/travel/travel-advice/10795765/Free-Wi-Fi-networks-the-worldsmost-connected-cities.html (accessed 1 September 2015).

Sturges, J.E. and Hanrahan, K.J. (2004) 'Comparing telephone and face-to-face qualitative interviewing: a research note', Qualitative Research, Vol. 4, No. 1, pp.107-118.

Suki, N.M., Ramayah, T. and Ly, K.K. (2011) 'Empirical investigation on factors influencing the behavioral intention to use Facebook', Universal Access in the Information Society, Vol. 11, No. 2, pp.223-231, https://doi.org/10.1007/s10209-011-0248-6.

Sullivan, J.R. (2013) 'Skype: an appropriate method of data collection for qualitative interviews?', The Hilltop Review, Vol. 6, No. 1, p.10.

Temkar, R., Gadekar, S. and Shah, D. (2015) 'Cloud based mobile application testing', International Journal of Science, Engineering and Technology Research, Vol. 4, No. 6 [online] http://ijsetr.org/wp-content/uploads/2015/06/IJSETR-VOL-4-ISSUE-6-2097-2102.pdf (accessed 1 September 2015).

Thomas, M. and Thomas, H. (2012) 'Using new social media and Web 2.0 technologies in business school teaching and learning', The Journal of Management Development, Vol. 31, No. 4, pp.358-367, https://doi.org/http://dx.doi.org.ezproxy.waikato.ac.nz/10.1108/ 02621711211219013.

Toninelli, A., Khushraj, D., Lassila, O. and Montanari, R. (2008) 'Towards socially aware mobile phones', in 7th International Semantic Web Conference, pp.68-75, Citeseer [online] http://citeseerx.ist.psu.edu/viewdoc/download?doi=10.1.1.357.2652\&rep=rep1\&type=pdf\#pag $\mathrm{e}=91$ (accessed 1 September 2015).

Triggs, R. (2015) 'Which voice calling app uses the most data per minute? We tested the top 10', 3 April [online] http://www.androidauthority.com/voice-call-data-comparison-598541/ (accessed 1 September 2015).

Trompenaars, A. and Hampden-Turner, C. (1997) Riding the Waves of Culture: Understanding Cultural Diversity in Business, 2nd ed., N. Brealey Pub., London.

Valkenburg, P.M., Peter, J. and Schouten, A.P. (2006) 'Friend networking sites and their relationship to adolescents' well-being and social self-esteem', CyberPsychology \& Behavior, Vol. 9, No. 5, pp.584-590, https://doi.org/10.1089/cpb.2006.9.584.

Verkamp, J. (2013) 'Patient loyalty and the social media effect', The Journal of Medical Practice Management: MPM, Vol. 29, No. 2, p.96.

Vodafone (2015) 'Why does my ADSL or VDSL broadband speed vary?' [online] http://help.vodafone.co.nz/app/answers/detail/a_id/5225/ /why-does-my-adsl-or-vdslbroadband-speed-vary\%3F (accessed 1 September 2015).

Wall, M. (2014) Big Data: Are you Ready for Blast-off?, 4 March [online] http://www.bbc.com/news/business-26383058 (accessed 7 October 2015).

Wallsten, S.J. and Riso, J. (2014) Residential and Business Broadband Prices Part 1: An Empirical Analysis of Metering and Other Price Determinants, Technology Policy Institute Working Paper [forthcoming] [online] http://works.bepress.com/scott_wallsten/59 (accessed 1 September 2015). 
West, J. and Mace, M. (2010) 'Browsing as the killer app: explaining the rapid success of Apple's iPhone', Telecommunications Policy, Vol. 34, Nos. 5-6, pp.270-286, https://doi.org/10.1016/ j.telpol.2009.12.002.

WhatsApp Inc. (2015) WhatsApp Web, 25 February, https://web.whatsapp.com - Firefox and Opera browsers are now supported! [microblog] [online] https://twitter.com/WhatsApp/status/ 570730905028808705 (accessed 1 September 2015).

Williams, A.L. and Merten, M.J. (2011) 'iFamily: internet and social media technology in the family context', Family and Consumer Sciences Research Journal, Vol. 40, No. 2, pp.150170, https://doi.org/10.1111/j.1552-3934.2011.02101.x.

Wood, E.J. (2006) 'The ethical challenges of field research in conflict zones', Qualitative Sociology, Vol. 29, No. 3, pp.373-386, https://doi.org/10.1007/s11133-006-9027-8.

Wright, K.B. (2005) 'Researching internet-based populations: advantages and disadvantages of online survey research, online questionnaire authoring software packages, and web survey services', Journal of Computer-Mediated Communication, Vol. 10, No. 3, https://doi.org/10.1111/j.1083-6101.2005.tb00259.x.

Yoon, C., Jeong, C. and Rolland, E. (2014) 'Understanding individual adoption of mobile instant messaging: a multiple perspectives approach', Information Technology and Management, Vol. 16, No. 2, pp.139-151, https://doi.org/10.1007/s10799-014-0202-4.

Zimmer, M. (2010) 'But the data is already public': on the ethics of research in Facebook', Ethics and Information Technology, Vol. 12, No. 4, pp.313-325, https://doi.org/10.1007/s10676-0109227-5.

\section{Notes}

1 Online research involves the use of several data collection channels such as e-mails, instant messages, voice and video calls and posts and discussions on social media.

2 Data usage is measured in units known as kilobyte (KB), megabyte (MB), or gigabyte (GB), with $1 \mathrm{MB}$ equals $1,000 \mathrm{~KB}$ and $1 \mathrm{~GB}$ equals $1,000 \mathrm{MB}$ (Wall, 2014).

3 The smartphone is "a mobile phone that performs many of the functions of a computer, typically having a touchscreen interface, internet access, and an operating system capable of running downloaded apps" (Oxford Dictionaries, 2015a).

4 Pseudonyms have been used through the paper. 